\title{
EVALUASI EFEKTIVITAS PENGGUNAAN DANA BANTUAN PENYELENGGARAAN (BOP) PAKET C PADA PUSAT PENDIDIKAN BELAJAR MASYARAKAT (PKBM) WIDYA SENTANA KABUPATEN BADUNG TAHUN 2018
}

\author{
Putu Dina Yuniarini, A.A. Gede Agung, Kadek Rihendra Dantes \\ Jurusan Administrasi Pendidikan \\ Universitas Pendidikan Ganesha \\ Singaraja, Indonesia
}

e-mail: dinayuniarini@gmail.com, agungtps2056@gmail.com

rihendra.dantes@pasca.undiksha.ac.id

\begin{abstract}
Abstrak
Kurang konsistennya kebijakan pemerintah terhadap petunjuk pelaksaan penggunaan dana BOP, yang menyebabkan efektivitas penggunaan dana BOP belum diketahui secara jelas. Oleh sebab itu penelitian ini bertujuan untuk mengevaluasi efektivitas penggunaan dana BOP Paket $\mathrm{C}$ Pada PKBM Widya Sentana Kabupaten Badung Tahun 2018. Sampel dalam penelitian ini berjumlah 35 sampel. Penelitian ini merupakan penelitian evaluasi yang menggunakan model evaluasi CIPP (context, input, process, product). Metode pengumpulan data dilakukan dengan penyebaran kuesioner. Analisis data menggunakan kriteria ideal lima skala. Hasil dari penelitian ini menunjukkan bahwa komponen variabel context dengan efektivitas sebesar $14,29 \%$, efektivitas variabel input sebesar $2,85 \%$, efektivitas variabel process sebesar $8,57 \%$, dan efektivitas variabel product sebesar $31,43 \%$. Sehingga dapat disimpulkan bahwa efektivitas penggunaan dana BOP dalam penelitian ini secara keseluruhan tergolong dalam kategori sangat efektif $(+,+,+,+)$ dengan skor mentah yang ditransformasikan kedalam t-score menghasilkan positif. Meskipun tergolong sangat efektif namun masih ada kendala-kendala yang dihadapi dalam penggunaan BOP baik dari variabel context, input, maupun process. Alternative pemecahan masalah yang disarankan: (1) melakukan subsidi silang untuk memenuhi kebutuhan peserta didik (2) lembaga selalu mengupdate dapodik dan data siswa agar semua mendapatkan BOP secara berkala, (3) melakukan pelaporan sebelum batas akhir pelaporann agar tidak terganggu oleh server yang down.
\end{abstract}

Kata kunci: BOP, Paket C, PKBM, Evaluasi, CIPP

\begin{abstract}
Lack of consistency in government policy towards the implementation guidelines for the use of the Operational Assistance Fund (BOP), which has made it clear the effectiveness of the use of BOP aid funds. Therefore, this study aims to evaluate the effectiveness of using operational assistance funds (BOP) Package C funds on PKBM Widya Sentana, Badung Regency in 2018. The samples in this study were 35 respondents. This research is an evaluation research that uses model evaluation method CIPP (context, input, process, product). Data were collected by questionnaire. Data analysis was done by ideal five scale. The results of this study indicate that the components of the context variable are classified as effectiveness of $14,29 \%$, the effectiveness of the input variable is 2,85\%, the effectiveness of the process variable is $8,57 \%$, and the effectiveness of the product variable is $31,43 \%$. So that it can be concluded that the effectiveness of the use of BOP in this study as a whole is effective $(+,+,+,+)$ with a raw score transformed into a $t$-score producing a positive. Although classified as effective, there are still challenges over using BOP from the variable's context, input, and process. Alternative solutions to problems are issued: (1) cross-subsidizing to meet the needs of students (2) institutions always update the data and data of students so that all get BOP regularly, (3) do reporting before the deadline so that it does not obstruct the server that is down.
\end{abstract}

Keywords: BOP, Package C, PKBM, Evaluation, CIPP

Jurnal Administrasi Pendidikan Indonesia | 132 


\section{PENDAHULUAN}

Pendidikan adalah usaha sadar dan terencana untuk mewujudkan suasana belajar dan proses pembelajaran agar peserta didik secara aktif mengembangkan potensi dirinya untuk memiliki kekuatan spiritual keagamaan, pengendalian diri, kepribadian, kecerdasan, akhlak mulia, serta keterampilan yang diperlukan dirinya, masyarakat, bangsa dan negara menurut Undang-Undang Nomor 20 Tahun 2003. Merujuk dari Undang-Undang Nomor 20 Tahun 2003 tersebut maka potensi diri yang meningkat ditandai dengan peningkatan kualitas diri dalam bidang ilmu pengetahuan (knowledge), keterampilan (skil), dan moral, mental, serta karakter (attitude) yang baik (Undang-Undang Nomor 20 Tahun 2003).

Undang-Undang Dasar Tahun 1945 menyebutkan bahwa salah satu tujuan Negara adalah mencerdaskan kehidupan bangsa. Mengingat luasnya wilayah Negara Kesatuan Republik Indonesia, keadaan geografis, dan sosial budaya ekonomi yang beragam banyak warga yang tidak terjangkau layanan pendidikan melalui jalur formal (sekolah). Berdasarkan permasalahan tersebut, untuk memperluas akses pendidikan dalam menjangkau daerahdaerah sulit dan memberikan layanan kepada masyarakat yang mengalami kesulitan ekonomi pemerintah menyelenggarakan pendidikan melalui jalur nonformal.

Tujuan pendidikan non formal adalah mewujudkan masyarakat pembelajar sepanjang hayat, meningkatkan kualitas keterampilan dan kecakapan hidup yang di perlukan untuk mengembangkan diri, meningkatkan profesionalitas sehingga masyarakat dapat memperoleh kesejahteraan, memenuhi kebutuhan belajar masyarakat yang tidak di peroleh dari pendidikan formal. Salah satu lembaga pendidikan nonformal adalah Pusat Kegiatan Belajar Masyarakat (PKBM). Pusat Kegiatan Belajar Masyarakat merupakan pusat seluruh kegiatan belajar masyarakat dalam rangka meningkatan pengetahuan, keterampilan/keahlian, hobi atau bakatnya yang dikelola dan diselenggarakan sendiri oleh masyarakat (Kamil, 2009: 85).

Penyelenggaraan pendidikan melalui jalur nonformal ditujukan bagi masyarakat yang karena sesuatu hal tidak berkesempatan mengikuti pendidikan melalui jalur formal, salah satunya melalui Pendidikan Kesetaraan Paket C/Pendidikan Vokasi Bagi Paket C Tahun 2018.

Program Bantuan Operasional Pendidikan selanjutnya disebut BOP Pendidikan Kesetaraan Paket C/Pendidikan Vokasi Bagi Paket C Tahun 2018 adalah layanan pendidikan melalui jalur pendidikan nonformal yang ditujukan bagi masyarakat yang karena berbagai faktor tidak dapat menyelesaikan pendidikannya atau putus sekolah ditingkat SMA/SMK/MA, yang diselenggarakan oleh lembaga/organisasi atau satuan pendidikan nonformal sehingga pada gilirannya lulusannya diharapkan memiliki pengetahuan, keterampilan, dan sikap yang dinyatakan dan diakui setara dengan lulusan SMA/MA.

Dalam rangka memberikan kesempatan bagi mereka untuk memperoleh layanan pendidikan dasar untuk mendukung wajib belajar pendidikan dasar dua belas tahun, pemerintah menyelenggarakan program pendidikan kesetaraan Paket C Setara SMA/MA. Untuk mensukseskan layanan program ini, pemerintah menyediakan bantuan sejumlah dana yang akan digunakan oleh para pimpinan lembaga/organisasi atau satuan pendidikan nonformal sebagai penyelenggara program pendidikan kesetaraan di daerah.

Berdasarkan Peraturan Direktur Jendral Pendidikan Anak Usia Dini dan Pendidikan Masyarakat Kementrian Pendidikan dan Kebudayaan Nomor 13 Tahun 2018 tentang Petunjuk Teknis Bantuan Operasional Penyelenggaraan Pendidikan Kesetaraan Paket C/Pendidikan Vokasi Bagi Paket C Tahun 2018. BOP Pendidikan Kesetaraan Paket C adalah sejumlah dana yang diberikan kepada lembaga penyelenggara program yang digunakan untuk mendukung proses pembelajaran program Pendidikan Kesetaraan Paket C.

Wirawan (2011:17) menyatakan evaluasi program adalah metode sistematik untuk mengumpulkan, menganalisis, dan memakai informasi untuk menjawab pertanyaan dasar mengenai program. Terdapat delapan jenis model evaluasi menurut Stufflebeam et al. (dalam Sunu, 2010) menjelaskan elemen dasar dari model CIPP ke dalam tiga lingkaran konsentris dan menggambarkan pentingnya pusat nilai yang ditetapkan. 
Stufflebeam et al. (2007:334) Model CIPP memiliki empat unsur yang berkesinambungan. Pertama, evaluasi konteks utamanya mengarah pada identifikasi kekuatan dan kelemahan organisasi dan pada pemberian masukan untuk memperbaiki organisasi. Kedua, evaluasi input teristimewa dimaksudkan untuk membantu menentukan program guna melakukan perubahan-perubahan yang dibutuhkan. Ketiga, evaluasi proses pada dasarnya memeriksa pelaksanaan rencana yang telah ditetapkan. Keempat, evaluasi produk bertujuan untuk mengukur, menafsirkan, dan menilai capaian-capaian program.

Efektifitas adalah bagaimana suatu organisasi berhasil memanfaatkan sumber daya dalam usaha mewujudkan tujuan operasional (Mulyasa, 2002:82).

Adapun rumusan masalah yang diajukan dalam penelitian ini sebagai berikut: (1) Bagaimana efektivitas penggunaan dana BOP pendidikan kesetaraan Paket C PKBM Widya Sentana Kabupaten Badung ditinjau dari komponen context? (2) Bagaimana efektivitas penggunaan dana BOP pendidikan kesetaraan Paket C PKBM Widya Sentana Kabupaten Badung ditinjau dari komponen input? (3) Bagaimana efektivitas penggunaan dana BOP pendidikan kesetaraan Paket C PKBM Widya Sentana Kabupaten Badung ditinjau dari komponen process? (4) Bagaimana efektivitas penggunaan dana BOP pendidikan kesetaraan Paket C PKBM Widya Sentana Kabupaten Badung ditinjau dari komponen product? (5) Bagaimana efektivitas penggunaan dana BOP pendidikan kesetaraan Paket C PKBM Widya Sentana Kabupaten Badung ditinjau dari komponen context, input, process, product? (6) Apa saja kendala-kendala yang dihadapi dalam evaluasi efektivitas penggunaan dana BOP pendidikan kesetaraan Paket C PKBM Widya Sentana Kabupaten Badung dan bagaimana upaya pemecahannya?

Adapun tujuan penelitian yang diajukan dalam penelitian ini adalah sebagai berikut: (1) Untuk memperoleh informasi mengenai efektivitas penggunaan dana BOP pendidikan kesetaraan Paket C PKBM Widya Sentana Kabupaten Badung ditinjau dari komponen context, (2) Untuk memperoleh informasi mengenai efektivitas penggunaan dana BOP pendidikan kesetaraan Paket C PKBM Widya Sentana Kabupaten Badung ditinjau dari komponen input, (3) Untuk memperoleh informasi mengenai efektivitas penggunaan dana BOP pendidikan kesetaraan Paket C PKBM Widya Sentana Kabupaten Badung ditinjau dari komponen process, (4) Untuk memperoleh informasi mengenai efektivitas penggunaan dana BOP pendidikan kesetaraan Paket C PKBM Widya Sentana Kabupaten Badung ditinjau dari komponen product, (5) Untuk memperoleh informasi mengenai efektivitas penggunaan dana BOP pendidikan kesetaraan Paket C PKBM Widya Sentana Kabupaten Badung ditinjau dari komponen context, input, process, product, (6) Untuk mengetahui kendala-kendala yang dihadapi dalam evaluasi efektivitas penggunaan dana BOP pendidikan kesetaraan Paket C PKBM Widya Sentana Kabupaten Badung dan memberikan upaya pemecahannya.

\section{METODE}

Metode penelitian yang digunakan dalam penelitian ini adalah studi evaluasi, karena ingin mengevaluasi suatu program/kegiatan dalam satu unit tertentu, dalam hal ini adalah Evaluasi Efektivitas Penggunaan Dana BOP Pendidikan Kesetaraan Paket C PKBM Widya Sentana Kabupaten Badung Tahun 2018. Desain penelitian yang digunakan dalam penelitian ini adalah model evaluasi CIPP.

CIPP yang dimaksud meliputi: (1) evaluasi terhadap context yang memberikan informasi tentang: Kebijakan Terkait dengan BOP, Tujuan Program BOP, Kebutuhan dan Harapan, Peluang Pengembangan Diri, (2) evaluasi terhadap input yang memberikan informasi tentang: Sumber Daya Manusia, Sosialisasi/Pelatihan, Organisasi/Manajemen, Sarana dan Prasarana, Petunjuk Teknis Pelaksanaan BOP, Dana Operasional, (3) evaluasi terhadap process yang memberikan informasi tentang: Perencanaan Program, Proses penetapan alokasi BOP, Penyaluran Dana BOP, Pengambilan Dana, Pemanfaatan Dana , Pertanggung Jawaban Keuangan, Monitoring dan Evaluasi, (4) evaluasi terhadap product yang memberikan informasi tentang : output outcome. 
Agung (2017) yang menyatakan populasi adalah keseluruhan objek dalam suatu penelitian. Populasi didalam penelitian ini adalah Pusat Kegiatan Belajar Masyarakat (PKBM) Program Kesetaraan Paket $C$ yang melaksanakan program BOP. Teknik pengambilan sampel yang digunakan dalam penelitian ini adalah purposive sampling.

Sampel adalah sebagian dari jumlah dan karakteristik yang dimiliki oleh populasi tersebut (Sugiyono, 2013). Sampel dalam penelitian ini adalah 1 orang Ketua PKBM Widya Sentana, 1 orang Sekretaris PKBM Widya Sentana, 1 orang Bendahara PKBM Widya Sentana, 2 orang Pegawai Administrasi, 3 orang Operator dapodik, 27 orang Tutor yang mengetahui pelaksanaan program BOP pendidikan kesetaraan Paket C di PKBM Widya Sentana. Sehingga jumlah subjek keseluruhan berjumlah 35 orang.

Arikunto (2013) mengatakan bahwa instrument merupakan alat bantu bagi peneliti dalam menggunakan metode pengumpulan data. Instrumen adalah alat ukur yang digunakan untuk memperoleh data tentang variabel. Metode pengumpulan data dilakukan dengan penyebaran kuesioner. Analisa data menggunakan kriteria ideal skala lima dengan metode deskriptif kuantitatif. Data yang diperoleh kemudian di transformasikan ke dalam $T$ skor. Jika $\mathrm{T}>50$ adalah positif (+) dan jika $\mathrm{T} \leq 50$ adalah negatiF (-) dan dikonversikan ke dalam kuadran Glickman.

\section{HASIL DAN PEMBAHASAN}

Hasil dari penelitian ini menunjukkan bahwa komponen variabel context tergolong efektivitas sebesar $14,29 \%$, efektivitas variabel input sebesar $2,85 \%$, efektivitas variabel process sebesar $8,57 \%$, dan efektivitas variabel product sebesarn $31,43 \%$. Sehingga dapat disimpulkan bahwa efektivitas penggunaan dana BOP dalam penelitian ini secara keseluruhan efektif dengan skor mentah yang ditransformasikan kedalam t-score menghasilkan positif $(+,+,+,+)$.

Penggunaan dana BOP Paket C pada PKBM Widya Sentana Kabupaten Badung Tahun 2018 tergolong efektif ditinjau dari skor rata-rata (mean) pada variabel context adalah 53.69, variabel input adalah 77.14, variabel process adalah 89.89, variabel product adalah 52.23. Skor rata-rata (mean) CIPP sebesar 272.94 .

Kendala dan Alternative Pemecahan Masalah Pada variable context dari empat dimensi yang ada terdapat dua dimensi yang bernilai negative, dimensi tersebut adalah kebutuhan dan harapan dan peluang pengembangan diri. Dimensi kebutuhan dan harapan, peluang pengembangan diri pada lembaga PKBM yang membutuhkan dana BOP untuk seluruh peserta didik tetapi dana BOP yang diperoleh bertahap sehingga tidak semua peserta didik memperoleh dana BOP. Alternative pemecahan masalah yang dilakukan lembaga PKBM untuk memecahkan kendala pada dimensi ini adalah dengan melakukan subsidi silang untuk memenuhi kebutuhan peserta didik dan lembaga selalu mengupdate dapodik dan data siswa agar semua mendapatkan BOP secara berkala. melakukan sehingga tidak mempengaruhi output.

Pada variable input yang bernilai negative adalah Sumber Daya Manusia, sosialisasi, dan petunjuk teknis pelaksanaan BOP. Pada sumber daya manusia terdapat beberapa tutor yang belum memahami penggunaan dana BOP sehingga berpengaruh terhadap dimensi sosialisasi Program dana BOP kepada tutor dan tenaga kependidikan masih kurang mendalam sehingga belum memahami secara mendasar proses, penggunaan dan aturanaturan yang harus dilaksanakan dalam pengelolaan program dana BOP. Untuk menyikapi permasalahan tersebut dilakukan upaya rapat tutor untuk menjelaskan pelaksaan BOP yang pada perjalanan penggunaan dana. Hal yang juga bernilai negative pada variable input adalah petunjuk teknis pelaksanaan BOP. Pada Petunjuk Teknis Pelaksanaan program dana BOP terdapat perubahan berdasarkan pemanfaatan dana bantuan penyelenggaraan yang awalnya disusun berdasarkan petunjuk teknis nomor 13 tahun 2018 menjadi adendum nomor 2589/ C4.3/ PM/ 2018 sehingga berpengaruh pada saat proses penarikan dana dan pelaporan awal. Untuk menyikapi permasalahan tersebut lembaga PKBM melakukan koordinasi langsung dengan pusat Direktorat Jendral di Jakarta sehingga dimensi negative pada variabel input tidak mempengaruhi kwalitas peserta didik atau output dari peserta didik. 
Pada variable process yang bernilai negative adalah dimensi Pemanfaatan dana dan dimensi pertanggungjawaban. Pemanfaatan dana BOP yang berubah ditengah jalan membuat proses pelaporan menjadi terhambat dan dalam Pelaporan untuk pertanggungjawaban yang mengharuskan untuk upload data melalui web internet yang diakses seluruh Indonesia sering gangguan dan server down. Untuk menyikapi permasalahan tersebut lembaga melakukan pelaporan sebelum batas akhir pelaporann agar tidak terganggu oleh server yang down sehingga dimensi negative pada variabel process tidak berpengaruh terhadap variabel output. Peserta didik tetap mendapatkan pelayanan yang baik sesuai hak peserta didik mendapatkan ilmu dan proses pembelajaran.

Pada variabel product tidak mengalami kendala karena semua kendala yang berada pada variabel context, input, process, tidak mempengaruhi hasil akhir output dari peserta didik.

\section{SIMPULAN DAN SARAN}

Berdasarkan analisi dan temuan penelitian, dapat disimpulkan (1) Penggunaan dana BOP Paket C pada PKBM Widya Sentana Kabupaten Badung Tahun 2018 tergolong dalam kategori efektif. Ketercapaian kategori efektif dapat dikatakan terlaksana dengan baik karena semua komponen variable context yang terdiri dari kebijakan terkait dengan BOP, tujuan program BOP, kebutuhan dan harapan, peluang pengembangan diri, (2) Penggunaan dana BOP Paket C pada PKBM Widya Sentana Kabupaten Badung Tahun 2018 tergolong dalam kategori efektif. Ketercapaian kategori efektif dapat dikatakan terlaksana dengan baik karena semua komponen variable input yang terdiri dari sumber daya manusia, sosialisasi/ pelatihan, organisasi/ manajemen, sarana dan prasarana, petunjuk teknis pelaksanaan BOP, dana operasional, (3). Penggunaan dana BOP Paket C pada PKBM Widya Sentana Kabupaten Badung Tahun 2018 tergolong dalam kategori efektif. Ketercapaian kategori efektif dapat dikatakan terlaksana dengan bai karena semua komponen variable process yang terdiri dari perencanaan program, proses penetapan alokasi BOP, penyaluran dana BOP, pengambilan dana, pemanfaatan dana, pertanggung jawaban keuangan, monitoring dan evaluasi, (4). Penggunaan dana BOP Paket C pada PKBM Widya Sentana Kabupaten Badung Tahun 2018 tergolong dalam kategori efektif. Ketercapaian kategori efektif dapat dikatakan terlaksana dengan baiK karena semua komponen variable product yang terdiri dari output, (5). Penggunaan dana BOP Paket C pada PKBM Widya Sentana Kabupaten Badung Tahun 2018 tergolong dalam kategori efektif positif, (6). Kendala-kendala yang dihadapi selama penggunaan dana BOP Paket $C$ pada PKBM Widya Sentana Kabupaten Badung Tahun 2018 dapat diatasi dengan cara bekerja sama.

Berdasarkan simpulan yang telah dikemukakan diatas, maka dapat diajukan beberapa saran sebagai berikut: (1). Bagi Lembaga PKBM Penerima BOP agar tetap menjalin kerjasama dan berkoordinasi dengan pemerintah terkait kedepannya agar penggunaan dana BOP tetap berjalan lancar dan efektif, (2). Bagi Direktur Jendral agar memperhatikan jadwal penerimaan BOP agar jelas dan tidak terdapat perubahan juknis ditengah pernajalan penggunaan dana BOP, (3). Bagi peneliti lain agar dapat melanjutkan penelitian ini kecakupan yang lebih luas dan mendalam terutama dalam menganalisa kendala-kendala dan mencari solusi upaya yang tepat untuk menanganinya, sehingga penelitian selanjutnya dapat memberikan sumbangan ide atau pemikiran baru untuk kemajuan dan pengembangan studi evaluasi khususnya dibidang administrasi pendidikan.

\section{DAFTAR PUSTAKA}

Agung, A. A. G. \& Koyan, I Wayan. 2016. Evaluasi Program Pendidikan (Fungsi Manajemen Kontrol). (Tidak Dipublikasikan).

Agung, A. A. G. 2017. Metodologi Penelitian Kuantitatif. Singaraja: Undiksha

Arikunto, S. \& Safruddin Abdul Jabar. 2014. Evaluasi Program Pendidikan: Pedoman Teoretis Praktis Bagi Nahasiswa dan Praktisi Pendidikan. Jakarta: Bumi Aksara.

Arikunto, Suharsimi. 2013. Manajemen Penelitian. Jakarta: Rineka Cipta. 
Departemen Pendidikan Nasional, 2003. Undang-Undang Nomor 20 Tahun 2003, Tentang Sistem Pendidikan Nasional, Jakarta: Departemen Pendidikan Nasional

Direktur Jendral Pendidikan Anak Usia Dini dan Pendidikan Masyarakat Kementrian Pendidikan dan Kebudayaan, 2018. Peraturan Nomor 13 Tahun 2018 tentang Petunjuk Teknis Bantuan Operasional Penyelenggaraan Pendidikan Kesetaraan Paket C/ Pendidikan Vokasi Bagi Paket C Tahun 2018.

Divayana, Dewa Gede Hendra. 2015. Penggunaan Model CSE-UCLA Dalam Mengevaluasi Kualitas Program Aplikasi Sistem Pakar. SNATIA. Hal 165-168.

Kamil, Mustofa. 2009. Pendidikan Nonformal. Alfabeta. Bandung.

Koyan, I Wayan. 2007. Asesmen Dalam Pendidikan. Singaraja: Undiksha Press

McDavid, James C., \& Laura R.L. Hawthorn. 2006. Program Evaluation and Performance Measurement : An Introduction To PraCTICE. California: Sage Publications, Inc.

Mulyasa, E, 2002. Manajemen Berbasis Sekolah. Bandung: PT. Remaja Rosdakarya.

Siagian, P. Sondang. 2005. Fungsi-fungsi Manajemen. Jakarta: Bumi Aksara.

Stufflebeam, D.L \& Shinkfield, A.J. 2007. Evaluation Theory, Models, \& Applications. United States of America: Jossey Bass.

Sugiyono. 2013. Metode Penelitian Pendidikan Pendekatan Kuantitatif, Kualitatif, dan R\&D. Bandung: Alfabeta.

Sunu, I Gusti Ketut Arya. 2010. Disertasi: Pengelolaan Pendidikan Multikultural (Studi Kasus Pada SMP/MTS di Provinsi Bali. Bandung: UPI (tidak dipublikasikan).

Wirawan. 2011. Evaluasi Teori, Model, Standar, Aplikasi, dan Profesi. Jakarta: Rajawali Pers. 